\title{
WHAT DRIVES THE BELIEFS IN BITCOIN? - SURVEY RESULTS
}

\author{
Zuzana Rakovská ${ }^{1}$
}

DOI: https://doi.org/10.31410/ITEMA.2019.241

\begin{abstract}
This paper examines the factors that affect the sentiment towards bitcoin of the given population - their beliefs about the future development of investors' interest in bitcoin in two weeks, one month, and one-quarter period ahead. To do so, it employs data from a unique longitudinal survey, which was conducted in six waves during the period from September to December 2018 on a balanced sample of 141 university students. The variety of factors are considered in the study, such as the collection of socio-demographic factors, expectations about dynamics of popular currency pairs, the degree of financial knowledge, respondents overconfidence or the technology acceptance factor. Using the ordered probit for panel data, this study found the support for the above mentioned factors at least in the one studied horizon. Moreover, it was shown that respondents evaluate also the past returns of Bitcoin when shaping their beliefs.
\end{abstract}

Keywords: Sentiment, Cryptocurrencies, Economic Expectations, Longitudinal Survey.

\section{INTRODUCTION}

B itcoin, the most popular cryptocurrency, has been gaining increased attention since at least 2011 when it experienced the first abnormal profits. In the following years, its price rocketed even further, and many authors started to ask the question of what factors drove such extreme dynamics. Compared to fiat currencies, bitcoin is not traded by large, sophisticated institutions/ investors, and its value is not connected to the performance of a single country or to the political changes. Therefore, the answer could not be found in traditional economic or financial theories. One of the possible explanations could be linked to the behavioral concept of sentiment - the aggregate of population beliefs and emotions that are not justified by fundamental news. Even though the literature about the effects of sentiment on cryptocurrencies has been established already (Kristoufek, 2013, 2015; Bukovina \& Marticek, 2016; Mai et al., 2017; Kim et al., 2017), little is known about drivers of population beliefs towards these crypto assets.

There are some studies that employed survey data to examine various factors that affect ownership and purchase intention (Stix, 2019) or the adoption and usage (Nicholls, 2017; Henry, 2018) of cryptocurrencies, but those studies did not consider respondents expectations or beliefs about those assessed. Schuh \& Shy (2016) used the data from a question in Survey of Consumer Payment Choice from year 2015, which asked the respondents about the qualitative perceptions about future development of Bitcoin prices. Authors calculated the qualitative forecast errors out of those observations and analyzed their effects on the awareness, adoption and use of Bitcoin (and other cryptocurrencies). They suggested that respondents are not likely to correctly assess the future Bitcoin price in short periods.

The aim of this paper is to examine in panel settings the various factors that affect beliefs in the most popular cryptocurrency - Bitcoin. As suggested in the above mentioned studies, the aggregate level of beliefs in Bitcoin, or in other words - the sentiment towards Bitcoin, is the

Masaryk University, Faculty of Economics and Administration, Lipova 41a, 60200 Brno, Czech Republic 
powerful determinant of future price of this cryptocurrency. Understanding what components affect the aggregate sentiment on micro-level and what is the direction of this relation is hence an important task.

\section{BITCOIN SURVEY, DATA AND DESCRIPTIVE STATISTICS}

This study employs the balanced panel data from online longitudinal survey which was conducted in six waves (on bi-weekly basis) during the period from September 2018 to December 2018. The sample of respondents consists of all 141 students from the Faculty of Economics and Administration, Masaryk University, who were enrolled in the course Financial Markets in the winter semester of 2018/2019². Each wave lasted for five days (Monday - Friday) during which the students were able to respond. Figure 1 shows the dynamics of Bitcoin price (in US dollars) and the periods of individual waves.

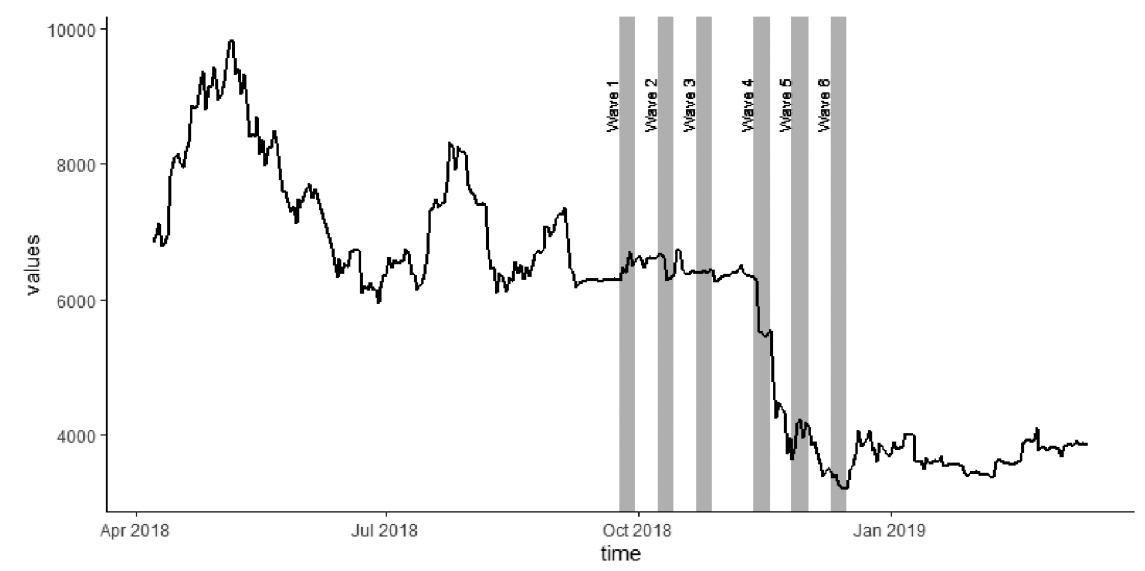

Figure 1. Bitcoin price (in US dollars) and the Survey Waves

Source: https://www.coindesk.com/

Survey was built in such a way that the completion of all its six waves, was the necessary condition for receiving the grade from the Financial Markets course. Therefore, each student had to respond to all six surveys before he or she was allowed to enter the final exam. In order to offset the unwilling effects of this mandatory approach, such as the tendencies of students to respond inaccurately or falsely to questions simply because the act of responding is what matters and not the content of the answers itself, each surveys included a contest scheme which yielded additional points for the "winning" students. In particular, each wave contained one or two guessing questions about the future exchange rate (price in US dollars) of Bitcoin in two weeks or in one month time and ten students with the most accurate guess for each of those guessing questions were rewarded by two points. Hence, the total of 16 additional points could have been received by any student. Because the minimum score for the students to pass the exam was 60 , it could be hypothesized that this reward scheme increased the overall quality of the survey responses compared to the situation without such incentives. The socio-demographic characteristics of respondents (see Table 1) suggest that the analysis might suffer from the sample selection bias all the respondents are young students of economic programs. Nevertheless, such a population could be considered to be the next generation of bankers, investors or accountants who will in turn shape the perceptions of community about financial innovations as a whole. Therefore, despite the relatively small and homogenous sample, this study could provide useful results that might indicate some interesting statistical relations.

2 The syllabus of the course is available on https://is.muni.cz/predmet/econ/podzim2018/BPF_FITR?lang=en. 
Table 1. Socio-Demographic Characteristics of Respondents

\begin{tabular}{|c|c|c|c|c|c|}
\hline & Number & $\%$ & & Number & $\%$ \\
\hline $\begin{array}{l}\text { Gender } \\
\text { Male } \\
\text { Female }\end{array}$ & $\begin{array}{l}68 \\
73\end{array}$ & $\begin{array}{l}48 \\
52\end{array}$ & $\begin{array}{l}\text { Age } \\
<25 \\
>=25\end{array}$ & $\begin{array}{c}136 \\
5\end{array}$ & $\begin{array}{c}96 \\
4\end{array}$ \\
\hline $\begin{array}{l}\text { Nationality } \\
\text { Czech or Slovak } \\
\text { Other }\end{array}$ & $\begin{array}{c}139 \\
2\end{array}$ & $\begin{array}{c}99 \\
1\end{array}$ & $\begin{array}{l}\text { Study Programmes } \\
\text { only econ. } \\
\text { econ. and other }\end{array}$ & $\begin{array}{l}114 \\
27\end{array}$ & $\begin{array}{l}81 \\
19\end{array}$ \\
\hline
\end{tabular}

Source: author

The main focus of the survey was respondents' sentiment towards Bitcoin as well as the overall awareness and usage of cryptocurrencies. Each wave contained two sets of questions. The first set, "longitudinal" questions, appeared in all the waves (or in the first wave and then in every second wave) and asked survey participants about they beliefs/expectations of the future development of Bitcoin exchange rate, as well as other national exchange rates or real estate prices. The reason for repeating the same questions in each wave was the fact, that the sentiment (optimistic/pessimistic beliefs about something) is not constant in time, therefore, by capturing its dynamics across individual waves, it is possible to examine what factors stand behind its high, low or unchanged value. The second set, "cross-sectional" questions, was aimed on respondents' socio-demographic characteristics or other characteristics related to cryptocurrencies that are time-invariant and therefore, it was unique for the given wave. This study employs only the part of the results from both sets and hence, represents the pioneering work, which utilizes the data from this longitudinal survey.

As discussed in the Introduction, the aim of this paper is to examine the various factors that drive population's beliefs about Bitcoin. As a measure of respondent's beliefs, the dependent variable, we used the results for the longitudinal question which appeared in all the survey waves and asked respondents the following: "How do you see investors' interest in Bitcoin in the horizon of two weeks/one month/one quarter?". There were five possible answers to this question: (1) substantial decline, (2) decline, (3) no change, (4) increase, and (5) substantial increase. It can be hypothesized that the respondent who believes in cryptocurrencies and expects increase in its demand would answer by either (4) increase or (5) substantial increase. Similarly, a person who is pessimistic about Bitcoin would most probably choose one of the first two answers. Note, that results for this question are available in three versions - horizons. Question about the two-week horizon was asked in all six waves, while the one-month and one-quarter horizon questions appeared only in the first, third and fifth wave. Figure 2 depicts histograms for those three dependent variables. It can be seen that respondents strictly prefer the middle three categories - increase, no change and decline, to the upper and bellow extreme categories in the first two considered horizons, while the no change responses in the horizon of one quarter reaches the same degree of preference as the extreme answers do. This might suggest that respondents do not expect extreme movements in the investors' interest towards Bitcoin in shorter periods. However, when one considers longer horizons, respondents seem to shift their neutral views to more polarized beliefs. Another interesting aspect is that the amount of pessimistic answers (decline) increases across waves. An explanation might be found in Figure 1, which shows that the price of Bitcoin in US dollars rapidly decreased during the survey period, which in turn, might have induced the spread of negative "sentiment".

Table 2 lists the explanatory variables (factors) that are used in this study together with their short characteristics and type of the question from which they were constructed. Variable fintest and overconf were constructed as the first principal component of the several cross-sectional questions. There are two reasons for applying the principal component analysis (PCA). Firstly, 
by employing only one variable instead of four or five, the amount of controls in the regression is reduced; which has in turn positive effects on the estimation properties. Secondly, both financial literacy and over confidence, are latent concepts that could not be directly measured. By observing several manifestations of those behaviors via several well-aimed questions and then by capturing only the common component, construction of more representative measure was available of either financial literacy or overconfidence.
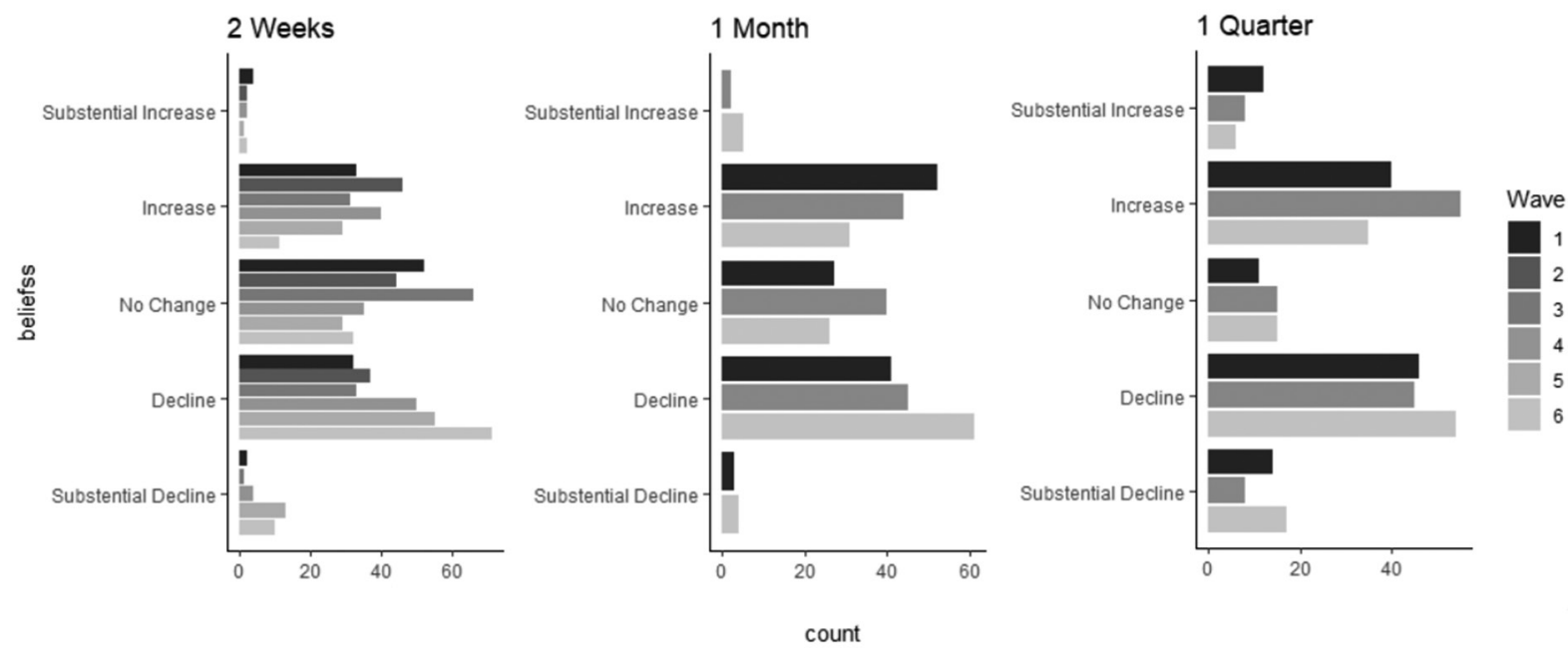

Figure 2. Histogram of Bitcoin price (in US dollars) and the Survey Waves

Source: author

Table 2. Description of Explanatory Variables

\begin{tabular}{|l|l|l|l|}
\hline Variable Name & Survey Question & Type & Characteristics \\
\hline male & What is your gender? & CS & Dummy: 1 if male, 0 if female \\
\hline other_than_econ & - & CS & $\begin{array}{l}\text { Dummy: 1 if the student studies other } \\
\text { programme besides the economics and } \\
\text { 0 otherwise }\end{array}$ \\
\hline fintest & - & CS & $\begin{array}{l}\text { index of financial literacy which was } \\
\text { created as the first principal component } \\
\text { of four dummy variables }{ }^{3} \text { (1 if the } \\
\text { student respondent to the financial } \\
\text { question correctly and 0 otherwise) }\end{array}$ \\
\hline overconf & - & CS & $\begin{array}{l}\text { index of overconfidence which was } \\
\text { oreated as the first principal component } \\
\text { of five dummy variables }(1 \text { if the } \\
\text { student exhibited overconfidence and 0 } \\
\text { otherwise) }\end{array}$ \\
\hline pref_crypto_all & - & $\begin{array}{l}\text { Dummy: 1 if the student answered } \\
\text { at least once that he/she prefers the } \\
\text { investment in cryptocurrencies to } \\
\text { other financial and real assets, and 0 } \\
\text { otherwise }\end{array}$ \\
\hline
\end{tabular}

3 The first question was aimed at the overall understanding of field of finance (interest rates, inflation, risks), the second question focused on returns in the financial market and the third and fourth questions asked students about the exchange rates.

$4 \quad$ Two dummies were created by evaluating students over confidence when answering the question whether they think they would receive the points from the given survey. Two dummies were constructed as the indication of students' over confidence in receiving the concrete grade from the Financial Markets course (the question was asked firstly in the second wave and then in the sixth wave). The last dummy was built from the students' assessment of the overall ability to obtain more points in total than others. 


\begin{tabular}{|l|l|c|l|}
\hline Variable Name & Survey Question & Type & Characteristics \\
\hline $\begin{array}{l}\text { late_majority, } \\
\text { early_majority, } \\
\text { early_adopter, } \\
\text { technology_ } \\
\text { enthusiast }\end{array}$ & $\begin{array}{l}\text { In relation to the adoption of new } \\
\text { technologies, I would describe myself as: } \\
\text { laggard, late majority, early majority, } \\
\text { early adopter or technology enthusiast?5 }\end{array}$ & CS & $\begin{array}{l}\text { Dummy: 1 if the respondent marks the } \\
\text { given category and 0 otherwise (base } \\
\text { category is laggard) }\end{array}$ \\
\hline czkeur_neg_2w & $\begin{array}{l}\text { How do you expect the exchange rate of } \\
\text { the Czech crown (CZK) to the euro (EUR) } \\
\text { to develop in the horizon o 2 weeks? }\end{array}$ & L & $\begin{array}{l}\text { Dummy: 1 if the respondent expects } \\
\text { decline and 0 otherwise }\end{array}$ \\
\hline eurusd_neg_2w & $\begin{array}{l}\text { How do you expect the exchange rate of } \\
\text { the euro (EUR) to the US dollar (USD) to } \\
\text { develop in the horizon o 2 weeks? }\end{array}$ & L & $\begin{array}{l}\text { Dummy: 1 if the respondent expects } \\
\text { decline and 0 otherwise }\end{array}$ \\
\hline realest_neq_1q & $\begin{array}{l}\text { In your opinion, how will real estate } \\
\text { prices in the Czech Republic evolve } \\
\text { within one quarter? }\end{array}$ & $\begin{array}{l}\text { Dummy: 1 if the respondent expects } \\
\text { decline and 0 otherwise }\end{array}$ \\
\hline btcret_14d & \multicolumn{1}{c}{ - } & $\begin{array}{l}\text { average returns of Bitcoin price in USD } \\
\text { over last 14 days that directly preceded } \\
\text { the day when the respondent completed } \\
\text { the survey (returns are calculated as } \\
\text { simple returns in percent) }\end{array}$ \\
\hline
\end{tabular}

Note: CS - cross-sectional type of question, L - longitudinal type of question

Source: author

\section{DRIVERS OF BELIEFS IN BITCOIN - RESULTS}

In order to assess the effects of selected explanatory variables on the panel of respondents' beliefs in Bitcoin, it was decided to use ordered probit model for panel data ${ }^{6}$. The choice of model follows the nature of the dependent variable which is in its sense represented by ordered choice between (1) substantial decline and (5) substantial increase. The description of the model could be found for example in Greene (2012, p. 787), who also states that one needs to be very careful in interpreting the coefficients of this model because the standard interpretation known from OLS models does not apply. The most practical way of interpreting the results is by so called predicted probabilities when the predictor is set to a concrete value and the rest of the variables are in their mean values.

Table 3 reports the estimated coefficients from running three regressions, one for each dependent variable: Bitcoin beliefs in 2-week horizon (btctrend_2w), 1-month horizon (btctrend_lm) and 1-quarter horizon (btctrend_lq). The table lists also the cutpoints (Cutl to Cut4) on the latent variable that are used to differentiate extreme pessimism from pessimism (Cut1), then the pessimism from neutrality (Cut2) and so on when values of the predictor variables are evaluated at zero. No measure of R-squared is available after running the ordered probit for panel data, but the value of likelihood ratio chi-square statistics for all the three specifications suggest that the models as a whole are statistically significant, as compared to the null model with no predictors.

\footnotetext{
$5 \quad$ Innovators are characterized by a high level of willingness to invest in new technologies, test and share their experience with other similarly focused people or groups. Early adopters differ from innovators by being more cautious about news, but they are one of the first people to adopt new technology and influence others with their opinions. Early majority fully embraces innovative technologies after a longer period of time (later than the previous two groups) and he/she rarely affects others. Late majority is someone who is conservative and is characterized by a great deal of caution. By adopting technology, late majority is trying to keep up with groups that have already adopted them. Laggard is defined as someone who accept innovative technologies at a time when they are already commonplace.

$6 \quad x t o p r o b i t$ command in Stata was used to process the estimation.
} 
From the results in Table 3, it can be concluded that the variety of significant factors that impact beliefs in Bitcoin differ for the three horizons. Not surprisingly, the average past returns of Bitcoin represent a significant driver of respondents' expectations, which means that respondents evaluate the historical evolution of this crypto-currency when shaping the beliefs. Students' assessment of the future dynamics of exchange rates (czkeur_neq_2w and eurusd_neg_2w) as well as their expectations about the future prices of real estate in the Czech Republic (realest_neq_lq) turned to be significant drivers as well; however, the effect is not maintained in all three specifications.

Table 3. Ordered Probit for Panel Data - Estimated Coefficients

\begin{tabular}{|c|c|c|c|c|c|c|}
\hline \multirow[b]{2}{*}{ Explanatory Var. } & \multicolumn{2}{|c|}{$\begin{array}{c}\text { (1) } \\
\text { btctrend_2w }\end{array}$} & \multicolumn{2}{|c|}{$\begin{array}{c}\text { (2) } \\
\text { btctrend_1m }\end{array}$} & \multicolumn{2}{|c|}{$\begin{array}{c}(3) \\
\text { btctrend_1q }\end{array}$} \\
\hline & Coef. & S.E. & Coef. & S.E. & Coef. & S.E. \\
\hline male & -0.131 & $(0.107)$ & $-0.465^{* * *}$ & $(0.161)$ & $-0.472^{* * *}$ & $(0.161)$ \\
\hline other_than_econ & $-0.217^{*}$ & $(0.126)$ & -0.0147 & $(0.189)$ & 0.174 & $(0.188)$ \\
\hline finlit & $0.220^{* *}$ & $(0.101)$ & $0.380^{* *}$ & $(0.151)$ & -0.0798 & $(0.150)$ \\
\hline overconf & 0.0530 & $(0.0526)$ & $0.168^{* *}$ & $(0.0787)$ & 0.0720 & $(0.0779)$ \\
\hline pref_crypto_all & $0.218^{*}$ & $(0.123)$ & $0.331^{*}$ & $(0.183)$ & 0.218 & $(0.182)$ \\
\hline late_majority & 0.248 & $(0.321)$ & 0.554 & $(0.485)$ & -0.0483 & $(0.478)$ \\
\hline early_majority & 0.285 & $(0.297)$ & 0.588 & $(0.449)$ & 0.0292 & $(0.442)$ \\
\hline early_adopter & 0.367 & $(0.314)$ & 0.678 & $(0.474)$ & 0.319 & $(0.468)$ \\
\hline technology_enthusiast & 0.398 & $(0.456)$ & $1.265^{*}$ & $(0.712)$ & 0.166 & $(0.702)$ \\
\hline czkeur_neg_2w & -0.0781 & $(0.101)$ & 0.0713 & $(0.166)$ & -0.130 & $(0.160)$ \\
\hline eurusd_neg_2w & $-0.249^{* * *}$ & $(0.0950)$ & $-0.274^{*}$ & $(0.145)$ & -0.194 & $(0.141)$ \\
\hline realest_neg_lq & $-0.348^{* *}$ & $(0.140)$ & -0.358 & $(0.228)$ & $-0.470^{* *}$ & $(0.224)$ \\
\hline btcret_14d & $0.255^{* * *}$ & $(0.0421)$ & $0.112^{* *}$ & $(0.0494)$ & $0.0960^{* *}$ & $(0.0478)$ \\
\hline Cut1 & $-1.791^{* * *}$ & $(0.334)$ & $-1.878^{* * *}$ & $(0.509)$ & $-1.686^{* * *}$ & $(0.490)$ \\
\hline Cut2 & -0.0900 & $(0.323)$ & 0.347 & $(0.489)$ & -0.209 & $(0.483)$ \\
\hline Cut3 & $0.898^{* * *}$ & $(0.324)$ & $1.101^{* *}$ & $(0.491)$ & 0.116 & $(0.483)$ \\
\hline Cut4 & $2.603^{* * *}$ & $(0.350)$ & $3.155^{* * *}$ & $(0.535)$ & $1.603^{* * *}$ & $(0.493)$ \\
\hline$N$ & 767 & & 381 & & 381 & \\
\hline chi2 & 65.36 & & 33.40 & & 23.98 & \\
\hline
\end{tabular}

Notes: $* p<0.10, * * p<0.05, * * * p<0.01$

Source: author's calculations in Stata

Table 4: Predicted Probabilities for finlit

\begin{tabular}{|c|c|c|}
\hline Outcome of btctrend_2w & Pred. Prob. for finlit= 0 & Pred. Prob. for finlit = 1 \\
\hline Substantial decline (1) & 0.039 & 0.024 \\
\hline Decline (2) & 0.399 & 0.334 \\
\hline No change (3) & 0.343 & 0.358 \\
\hline Increase (4) & 0.210 & 0.270 \\
\hline Substantial increase (5) & 0.008 & 0.015 \\
\hline
\end{tabular}

Source: author's calculation using Stata

Table 4 lists the calculated predicted probabilities for one interesting relation found in the first model specification: the effect of finlit on btctrend_2w. The rest of the predicted probabilities are not reported due to paper-size limitations. For example, the probability of respondents having optimistic beliefs (Increase (4)) when the financial literacy score is equal to 1 (all the financial questions were answered correctly) and the rest of the variables are at their means is $27 \%$. Interestingly, the middle three options seems to have similar probability for both extreme finlit values ( inlit $=1$ and finlit $=0$ ) which corresponds to the way how the responses are structured as demonstrated in Figure 1. Nevertheless, the further examination of the effects is left for the future research. 


\section{CONCLUSION}

This paper examined the factors, both time-variant and time-invariant, that affect overall beliefs about the most popular cryptocurrency - Bitcoin. The data from the unique longitudinal survey were employed and the survey was conducted on the sample of university students in six waves during the last four months of 2018. Respondents' beliefs were measured by ordered-choice variable which manifests the expectation about the dynamics of the investors' interest in Bitcoin. Such a variable could be viewed as a direct measure of sentiment - if the survey participant is optimistic (pessimistic) about the future development of Bitcoin, he/she would probably respond that they expect substantial increase or increase (substantial decline or decline) in investors' demand for Bitcoin.

The results of the ordered probit model for panel data showed that respondents evaluate not only the past returns of Bitcoin when shaping their beliefs but also, the way how they expect the development of the exchange rates of national currencies matters. Several factors have significant effects on Bitcoin beliefs from which the most interesting are financial literacy, degree of preference of Bitcoin to other assets or the respondents' overconfidence. This study represents the first application of the unique panel dataset that results from the subject longitudinal survey and pioneer attempt to analyze the drivers of Bitcoin beliefs of individuals in the Czech Republic environment.

\section{ACKNOWLEDGMENT}

The support from Masaryk University under project MUNI/A/1028/2018 is gratefully acknowledged.

\section{REFERENCES}

Bukovina, J., \& Martiček, M. (2016). Sentiment and bitcoin volatility (No. 2016-58). Mendel University in Brno, Faculty of Business and Economics.

Greene, W. (2012). H.(2012): Econometric Analysis.

Henry, C. S., Huynh, K. P., \& Nicholls, G. (2018). Bitcoin awareness and usage in Canada. Journal of Digital Banking, 2(4), 311-337.

Kim, Y. B., Lee, J., Park, N., Choo, J., Kim, J. H., \& Kim, C. H. (2017). When Bitcoin encounters information in an online forum: Using text mining to analyse user opinions and predict value fluctuation. PloS one, 12(5), e0177630.

Kristoufek, L. (2013). BitCoin meets Google Trends and Wikipedia: Quantifying the relationship between phenomena of the Internet era. Scientific reports, 3, 3415.

Kristoufek, L. (2015). What are the main drivers of the Bitcoin price? Evidence from wavelet coherence analysis. PloS one, 10(4), e0123923.

Mai, F., Shan, Z., Bai, Q., Wang, X., \& Chiang, R. H. (2018). How does social media impact Bitcoin value? A test of the silent majority hypothesis. Journal of Management Information Systems, 35(1), 19-52.

Nicholls, G. (2017, September). Bitcoin awareness and usage in Canada. In Canadian Stata Users' Group Meetings 2017 (No. 08). Stata Users Group.

Schuh, S., \& Shy, O. (2016). US consumers' adoption and use of Bitcoin and other virtual currencies. In DeNederlandsche bank, Conference entitled "Retail payments: mapping out the road ahead.

Stix, H. (2019). Ownership and purchase intention of crypto-assets-survey results (No. 226). 